\title{
Mixed Epithelial and Mesenchymal Hepatoblastoma with Teratoid Features-A Diagnostic Dilemma
}

\author{
Yogesh Kumar Sarin* and Parveen Kumar \\ Department of Paediatric Surgery, Maulana Azad Medical College, India
}

*Corresponding author: Dr. Yogesh Kumar Sarin, Director Professor \& Head, Department of Paediatric Surgery, Maulana Azad Medical College, New Delhi-110002, INDIA

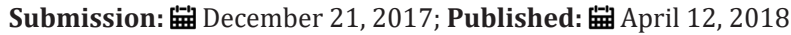

\begin{abstract}
We report $1 \frac{1}{2} 2$-year-old boy harboring mixed epithelial and mesenchymalhepatoblastoma with teratoid features. The diagnostic dilemma in the present case is presented and review of literature of the entity is done.

Keywords: Hepatoblastoma; Mesenchymal; Epithelial; Teratoid Features; Abdominal examination; Epigastric; Umbilical; Anaemia

Abbreviations: MEM: Mixed Epithelial and Mesenchymal; HBL: Hepatoblastoma; THBL: Teratoid Hepatoblastomas; USG: Ultrasonography; CECT:

Contrast Enhanced Computerised Tomography; VMA: Vanillylmandelic Acid
\end{abstract}

\section{Introduction}

Mixed epithelial and mesenchymal (MEM) hepatoblastoma (HBL) with teratoid features, or teratoid hepatoblastomas (THBL) may mimic other pediatric tumors, especially teratomas, and their recognition can be challenging on imaging studies and in small biopsy samples [1]. This case emphasizes the importance of recognizing this rare and unusual variant of HBL.

\section{Case Report}

One and half-year-old boy was brought to us with a progressively increasing right-sided abdominal lump noticed since last 7 months. There was no other associated constitutional complaint. On examination, patient had stable vitals but gross pallor. Abdominal examination revealed a $15 \times 15 \mathrm{~cm}$ firm, immobile, non-tender mass with lobulated surface with ill-defined margins in the right lumbar, right hypochondriac, epigastric, umbilical and right iliac fossa regions. Liver margin could not be palpated separately. Rest of the systemic examination was normal. Investigations revealed severe anaemia with $(\mathrm{Hb} 3.4 \mathrm{gm} / \mathrm{dl})$. His renal and liver function tests were essentially normal with slight rise in AST level of $183 \mathrm{U} / \mathrm{l}$. $\mathrm{X}$-ray abdomen showed coarse calcifications in the area of the mass (Figure 1). Ultrasonography (USG) revealed a large solid lesion in right lumbar region with coarse calcification and vascularity; organ of origin could not be estimated accurately. Liver showed two target lesions in segment VII and VIII. Contrast enhanced computerised tomography (CECT) showed $11.5 \times 9 \mathrm{~cm}$ predominantly exophytic, mildly enhancing mass lesion of having solid and cystic components having large calcifications; there were ill-defined planes between the mass and inferior margin of right lobe of liver (Figure $2 \&$ 3 ). The mass was attenuation inferior vena cava posteriorly and displacing the portal vein superiorly, however both the vessels showed normal contrast opacification. The liver measured $12 \mathrm{~cm}$ with a well-defined mildly enhancing lesion in superior segment of right lobe. Rest of the abdominal structures including spleen, bilateral kidneys, pancreas and thorax were normal. No abdominal lymphadenopathy or free fluid was noted.

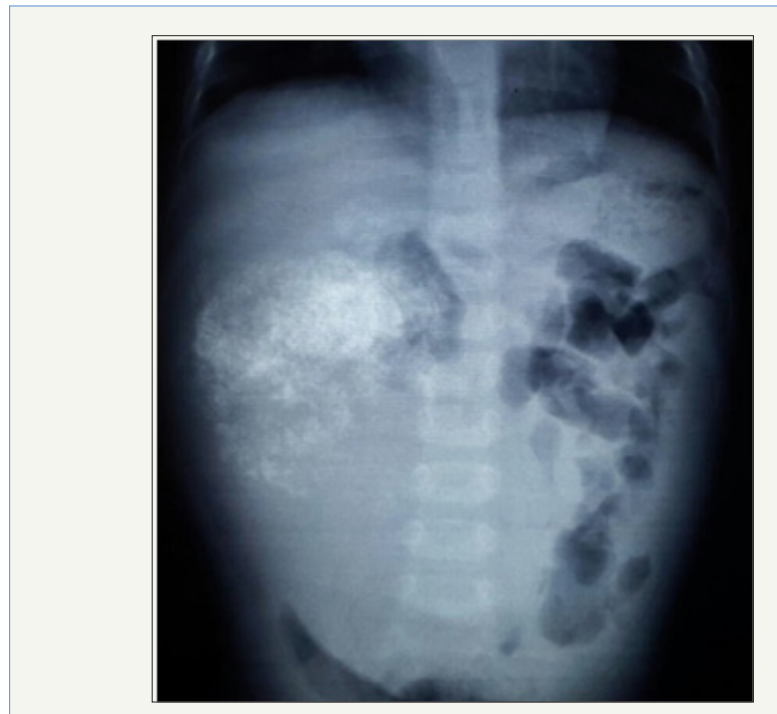

Figure 1: X-ray abdomen showing coarse calcifications in the area of the mass. 


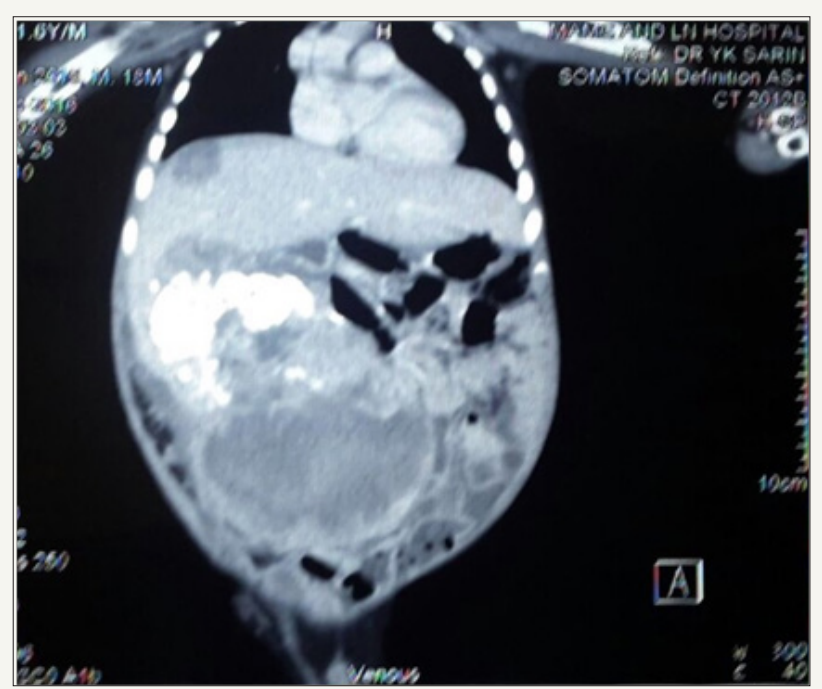

Figure 2: Initial CECT image showing exophytic mass with target lesion in segment VII.

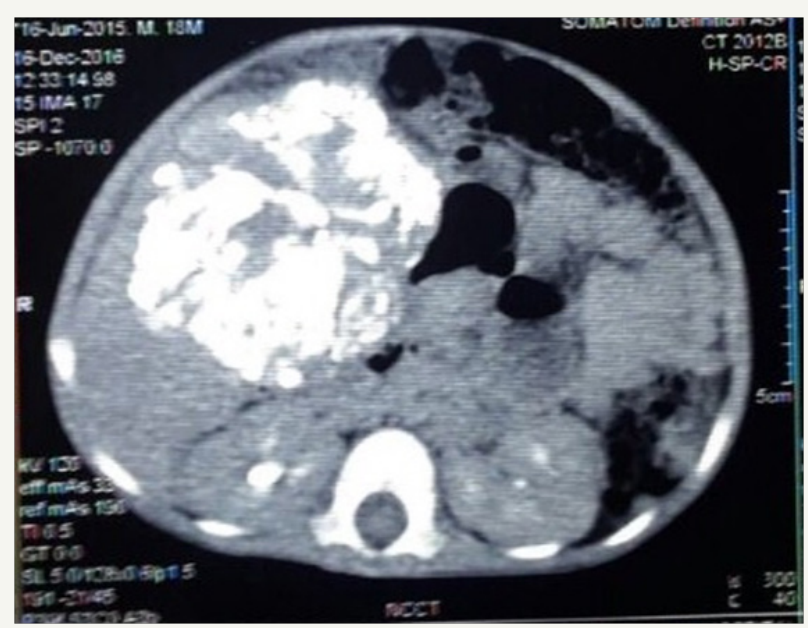

Figure 3: Initial CECT image showing extensive calcification.

Tumour markers showed raised $\alpha$-fetoprotien (AFP) of $>20000 \mathrm{ng} / \mathrm{ml}, \beta$-human chorionic gonadotrophin (HCG) was within normal (2.92mIU/l), LDH 1189U/l, 24-hour urinary vanillylmandelic acid (VMA) was normal $(0.29 \mathrm{mg} / \mathrm{l} / 24 \mathrm{hr})$. The Trucut biopsy was mainly necrotic and haemorrhagic but suggestive of germ cell tumor with neural elements.

In view of raised AFP and trucut biopsy findings, it was decided to start him on 2 cycles of bleomycin-etoposide-cisplatin (BEP) regime at 2/3rd reduced dose. CECT was repeated after 2 cycles; it showed evidence of reduction in the bulk of the lesion with disappearance of the cystic component of the tumor. AFP levels reduced marginally to $16923 \mathrm{ng} / \mathrm{ml}$.

This was followed by R1 resection of the tumor with a wedge of the inferior margin of the right lobe of liver, which appeared to be involved with the tumor. The final histopathology report came as a mixed hepatoblastoma with extensive osseous metaplasia infiltrating the surrounding liver (Figure 4); the resection margin was positive for tumor. The Hospital Tumor Board decided to administer him4 cycles of cisplatinum monotherapy. After 5 cycles, AFP levels came downto 5969ng/ml, but repeat CT showed that lesion in segments VII\& VIII had grown to $5 \mathrm{X} 5 \mathrm{~cm}$ size. On re-exploration, the tumor arising from the right lobe of liver was seen very firmly adherent to the right hemi-diaphragm was seen. No attempt to excise the tumor was done; the right portal vein was ligated so as to let left lobehypertrophy for a future right hepatectomy. The patient was started on cisplatin-doxorubicin (PLADO) combination regimen and received 5 cycles, and AFP levels dropped to $1210 \mathrm{ng} / \mathrm{ml}$. CT showed ill-marginated large heterogeneous enhancing mass in right lobe liver, with multiple calcific foci and necrotic areas within; left lobe was hypertrophied (Figure 5). He underwent right extended liver resection with partial excision of the adhered right hemi-diaphragm. Histopathology was reported as mixed HBL with predominant embroynal and fetal pattern. Large area of cartilage was identified with lympho-venous invasion and all margins were free. However, he succumbed to Klebsiella sepsis after this 3rd surgery on 7 th postoperative day, 9 months after initiation of the multimodal therapy.

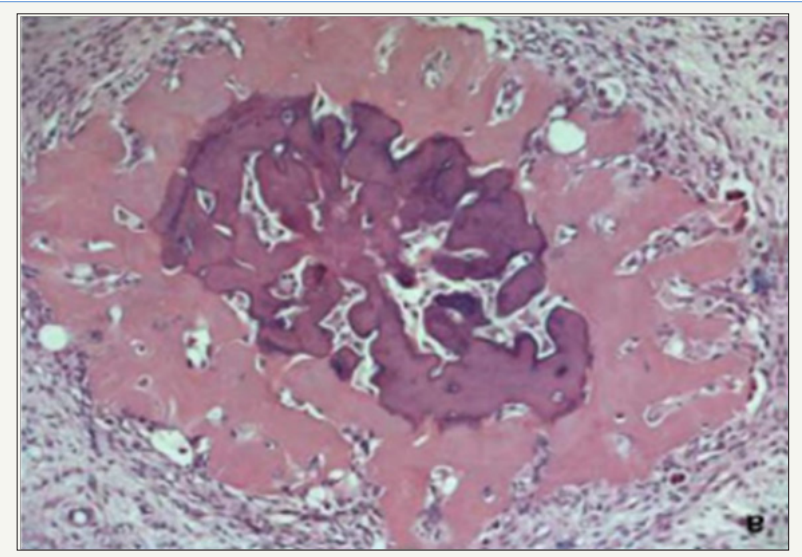

Figure 4: Histology picture showing osseous metaplasia.

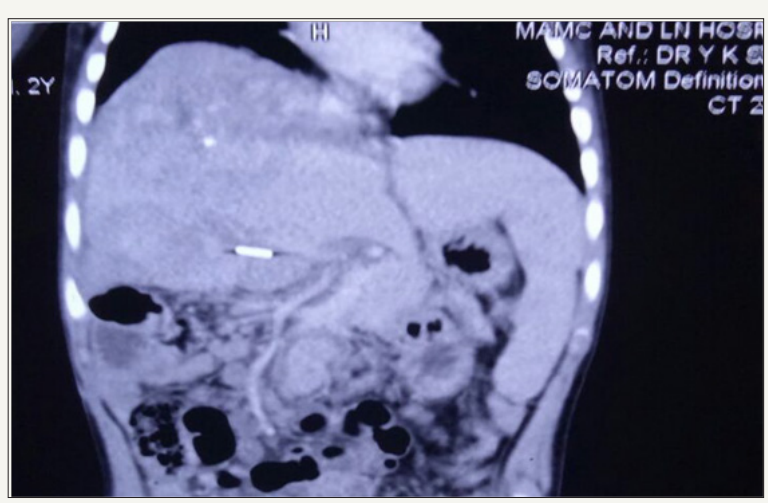

Figure 5: Last CECT image showing heterogenous mass in right lobe, clipped right portal vein and hypertrophied left lobe liver. 


\section{Discussion}

Approximately two-thirds of pediatric liver tumors are malignant and almost 70 percent of those are of hepato-cellular origin, either hepatoblastoma (HBL) or hepatocellular carcinoma (HCC) [2,3]. HBL is usually diagnosed in children less than 5 years of age and is the most common pediatric liver cancer. It is an embryonal tumor which is thought to arise from hepatocyte precursor cells and often recapitulates stages of liver development, and it is occasionally composed of combinations of epithelial, mesenchymal, and teratoid components $[3,4]$.

As per International Pediatric Liver Cancer Pathological Classification (2011), HBL is sub-classified as the wholly epithelial type and the mixed epithelial and mesenchymal (MEM) type [5]. The wholly epithelial type is further subdivided into welldifferentiated fetal (pure fetal with low mitotic activity), crowded fetal (mitotically active), embryonal, epithelial mixed, small cell undifferentiated, and cholangioblastic. The MEM type is subdivided into MEM without teratoid features and MEM with teratoid features.

What differentiates MEM type HBLs from wholly epithelial type is the additional presence of stromal derivatives including spindle fibroblastic cells, osteoid, skeletal muscle, and cartilage. When there is no other heterologous component, such as stratified squamous epithelium, epi-thelium containing mucus-producing cells, neuroglial tissue, melanin-containing cells and other elements, those tumors are classified as HBL MEM without teratoid features. When there is a heterologous component, those tumors are classified as HBL MEM with teratoid features.

MEM with teratoid features comprise of $4-10 \%$ of all HBLs [68]. Though Manivel et al [9] were the first to recognize this category of HBLs in 1986 and coined the term teratoid HBL, a similar tumor was reported by Misugi and Reiner in 1965 [10]. There were others who simply described them as mixed hepatoblastoma and teratoma of the liver [11,12]. To use one nomenclature or the other might be mostly semantic.This divergent differentiation is probably related to the pluripotential stem cell precursors, which have the ability to differentiate into all of these different components $[1,13]$. The osteoid tissue is produced by neoplastic, fibroblastic-like mesenchymal cells [14].

The initial abdominal imaging workup including ultrasound and contrast enhanced computerized tomography (CECT) in the index patient did not categorically reveal the organ of origin, and differential diagnoses of germ cell tumor and hepatoblastoma were considered. The trucut biopsy was also reported as germ cell tumor. Similar errors have been reported on small specimens earlier too [15]. One issue that needs to be highlighted is that small-cell undifferentiated HBL may overlap the morphological features of the entire group "small blue cell" pediatric neoplasms [15]. These coupled with our inexperience with the entity of MEM with teratoid features led to many management issues.

Had we made the correct diagnosis initially, we would have treated this case as that of HBL. The HBL treatment is relatively standardized, the only controversy matter between the European and American study groups being the time of the surgical intervention. The SIOPEL Group recommends the presurgical chemotherapy followed by the tumoral excision and then a short period of postsurgery chemotherapy [16]. The American study group recommends the surgical intervention when diagnosed (applicable on $50 \%$ of the patients) followed by postsurgical chemotherapy [17]. In general, we prefer presurgery chemotherapy for HBL in our department. Chemotherapy is only effective in the HBL areas and not the teratoid portion of the tumor [18]. It has been repeatedly seen previously that chemotherapy showed a morphological maturative or differentiating effect on such type of HBL and postchemotherapy excised specimens show prominence of mature teratoid tissues $[9,15,19,20]$. The probable explanation is that though the chemo-unresponsive teratoid elements were very likely present from the outset, they became more prominent after therapy, as the chemosensitive hepatoblastomatous component diminished.

The prognostic significance of this variant of HBL is still undetermined at present, although tumor histology of the MEM type has been considered a favorable prognostic factor by some investigators $[21,22]$.

\section{References}

1. Wang LL, Filippi RZ, Zurakowski D, Archibald T, Vargas SO, et al. (2010) Effects of neoadjuvant chemotherapy on hepatoblastoma: a morphologic and immunohistochemical study. Am J Surg Pathol 34: 287-299.

2. Finegold MJ (2004) Hepatic tumors in childhood. In: Russo P, et al. (Eds.), Pathology of Pediatric Gastrointestinal and Liver Disease. Springer, New York, USA.

3. Weinberg AG, Finegold MJ (1983) Primary hepatic tumors of childhood. Hum Pathol 14(6): 512-537.

4. Stocker JT (2001) Hepatic tumors in children. Clin Liver Dis 5(1): 259281.

5. Tanaka Y, Inoue T, Horie H (2013) International pediatric liver cancer pathological classification: current trend. Int J Clin Oncol 18: 946-954.

6. Rabah R (2012) Teratoid hepatoblastoma with abundant neuroendocrine and squamous differentiation with extensive parenchymal metastasis. Arch Pathol Lab Med 136: 911-914.

7. Finegold MJ, Lopez-Terrada DH, Bowen J, Washington MK, Qualman SJ (2007) Protocol for examination of specimens from pediatric patients with hepatoblastoma. Arch Pathol Lab Med 131: 520-529.

8. Ishak KG, Goodman ZD, Stocker JT (2001) Atlas of tumor pathology. Tumors of the liver and intrahepatic bile ducts. Armed Forces Institute of Pathology, 3rd series. Fascicle 31. Washington, USA.

9. Manivel C, Wick MR, Abenoza P, Dehner LP (1986) Teratoid hepatoblastoma: the nosologic dilemma of solid embryonic neoplasms of childhood. Cancer 57(11): 2168-2174.

10. Misugi K, Reiner CB (1965) A malignant true teratoma of liver in childhood. Arch Pathol 80(4): 409-412.

11. Conrad RJ, Gribbin D, Walker NI, Ong TH (1993) Combined cystic teratoma and hepatoblastoma of the liver: probable divergent differentiation of an uncommitted hepatic precursor cell. Cancer 72(10): 2910-2913.

12. Moll A, Krenauer A, Bierbach U, Till H, Hirsch W, et al. (2009) Mixed hepatoblastoma and teratoma of the liver in a 3-year-old child: a unique combination and clinical challenge. Diagn Pathol 4: 37. 
13. Ramsay AD, Bates AW, Williams S, Sebire NJ (2008) Variable antigen expression in hepatoblastomas. Appl Immunohistochem Mol Morphol 16(2): 140-147.

14. Silverman JF, Fu YS, McWilliams NB, Kay S (1975) An ultrastructural study of mixed hepatoblastoma with osteoid elements. Cancer 36(4): 1436-1443.

15. Buccoliero AM, Castiglione F, Maio V, Moncini D, Sardi I, et al. (2008) Teratoid hepatoblastoma. Fetal Pediatr Pathol 27(6): 274-281.

16. Perilongo G, Shafford E, Maibach R, Aronson D, Brugières L, et al. (2004) Risk-adapted treatment for childhood hepatoblastoma; final report of the second study of the International Society of Pediatric OncologySIOPEL2. Eur J Cancer 40(3): 411-421.

17. Ortega JA, Douglass EC, Feusner JH, Reynolds M, Quinn JJ, et al. (2000) Randomized comparison of cisplatin/vincristine/fluorouracil and cisplatin/continuous infusion doxorubicin for treatment of pediatric hepatoblastoma: A report from the Children's Cancer Group and the Pediatric Oncology Group. J Clin Oncol 18(14): 2665-2675.
18. Inoue M, Uccida K, Kohei O, Nashida Y, Deguchi T, et al. (2006) Teratoid Wilms' tumor: a case report with literature review. J Pediatr Surg 41(10): 1759-1763.

19. Forouhar FA, Quinn JJ, Cooke R, Foster JH (1984) The effect of chemotherapy on hepatoblastoma. Arch Pathol Lab Med 108(4): 311314 .

20. Kim L, Park YN, Kim SE, Noh TW, Park C (2001) Teratoid hepatoblastoma: multidirectional differentiation of stem cell of the liver. Yonsei Med J 42(4): 431-435.

21. Haas JE, Muczynski KA, Krailo M, Ablin A, Land V, et al. (1989) Histopathology and prognosis in childhood hepatoblastoma and hepatocarcinoma. Cancer 64: 1082-1095.

22. Ismail H, Broniszczak D, Kaliciński P, Dembowska BB, Perek D, et al. (2012) Changing treatment and outcome of children with hepatoblastoma: analysis of a single center experience over the last 20 years. J Pediatr Surg 47(7): 1331-1339.

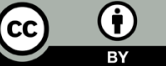

Creative Commons Attribution 4.0 International License

For possible submissions Click Here

\section{Submit Article}

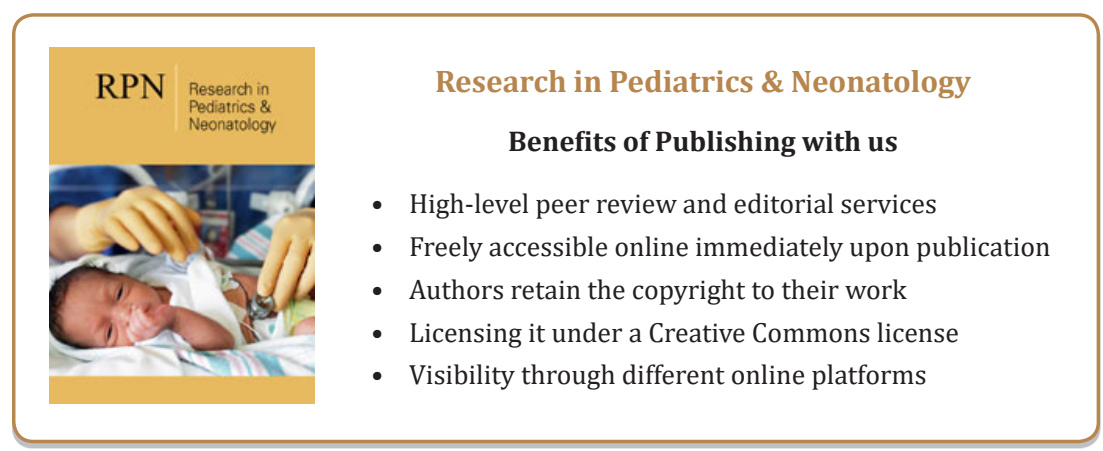

